\title{
A Minimal IncRNA-mRNA Signature Predicts Sensitivity to Neoadjuvant Chemotherapy in Triple-Negative Breast Cancer
}

\author{
Qian Wanga,b Chunmei Lic Peipei Tang ${ }^{c}$ Runyuan Jic Song Chen ${ }^{c}$ \\ Jian Wen ${ }^{a}$ \\ aDepartment of Breast Surgery, The Fourth Affiliated Hospital of China Medical University, Shenyang, \\ ${ }^{b}$ Department of Cardiac Function, The Fourth Affiliated Hospital of China Medical University, Shenyang, \\ Institute of Medicinal Biotechnology, Jiangsu College of Nursing, Huaian, China
}

\section{Key Words}

Triple-negative breast cancer • Neoadjuvant chemotherapy • Response - Gene signature • LncRNA

\begin{abstract}
Background/Aims: Triple-negative breast cancer (TNBC) is a highly aggressive malignancy that responds in a diverse manner to neoadjuvant chemotherapy (NAC). This study was aimed to uncover an RNA signature in TNBC patients which predicts pathological complete responses (pCR) to NAC by analyzing long noncoding RNA (IncRNA) and coding gene expression. Methods: Microarray datasets from 26 TNBC patients receiving NAC including ten patients showing pCR were obtained from the Gene Expression Omnibus database. Results: A total of 172 coding genes and 84 IncRNAs were differentially expressed between patients achieving pCR and those who did not. Filtering based on the predictive efficacy of response to NAC using receiver operator characteristic curve (ROC) and area under the curve (AUC) shortlisted 23 IncRNAs and 15 coding genes from consideration. Finally, a response score consisting of 1 IncRNA and 2 coding genes was developed: response score $=2.595{ }^{*} B P E S C 1-1.09 *$ WDR72 $1.428 *$ GADD45A - 0.731. The response score had good predictive performance (AUC $=0.931$, $p<0.01$ ) and at the cut-off of 0.545 , the response score had sensitivity and specificity of 0.8 and 0.9 , respectively. Conclusion: We propose a simple gene expression signature of only three RNA species could be employed clinically to predict PCR in TNBC patients receiving NAC.
\end{abstract}




\section{Cellular Physiology Cell Physiol Biochem 2018;48:2539-2548 \begin{tabular}{ll|l} 
DOI: 10.1159/000492698 & $\begin{array}{l}\text { O 2018 The Author(s). Published by S. Karger AG, Basel } \\
\text { www.karger.com/cpb }\end{array}$
\end{tabular}}

Wang et al.: A IncRNA-mRNA Signature Predicts NAC Response in TNBC

\section{Introduction}

Breast cancer is one of the most common types of malignant cancer worldwide and leads to about half a million deaths every year [1,2]. Neoadjuvant chemotherapy (NAC) in patients with advanced disease can enhance surgical opportunities, particularly making breast-conserving surgery more feasible in patients presenting with large tumors [2]. Moreover, patients demonstrating a pathological complete response (pCR) to NAC have better prognosis than those with partial responses or progressive disease [3-5]. NAC has been widely used for these reasons but nevertheless pCR rates for NAC are low. The National Surgical Adjuvant Breast and Bowel Project report the pCR rate as 40-50\% [6] while others suggest the rate may be even lower [7]. Thus, it is important to develop predictive markers for pCR to optimize the use of NAC.

Triple-negative breast cancer (TNBC) represents about 10\%-20\% of all breast cancer cases and is defined by lack of estrogen receptor (ER) and progesterone receptor (PR) expression as well as human EGFR2 (HER2) amplification [3, 4]. TNBC is more aggressive than other types of breast cancer, usually presenting larger size, higher grade, and more lymph node metastasis at diagnosis $[3,5,8]$. Presently there are no targeted therapies for TNBC and chemotherapy is the only choice of systemic treatment available. Notably, TNBCs are highly heterogeneous, and the same NAC chemotherapy regimen yield diverse responses. It is therefore urgent to develop clinically applicable biomarkers for TNBC to predict the response to NAC.

More than half of the human genome is known to be transcribed with the most abundant species, long noncoding RNAs (lncRNAs), these being defined as RNA transcripts larger than $200 \mathrm{nt}$ without coding capacity $[9,10]$. Indeed according to the Encyclopedia of DNA Elements (ENCODE) project, more than 16000 transcribed lncRNAs from human genome have been identified [11]. LncRNAs are principally regulatory molecules and have been shown to participate in a diverse array of biological functions. Not surprisingly, aberrant expression of lncRNAs occurs in disease and notably certain lnRNAs have been strongly implicated in the pathology of breast cancer [11-13]. LncRNA HOTAIR, for example, binds the polycomb repressive complex 2 to silence genes involved in chromatin remodeling [14,15]. Compared with coding genes, lncRNAs are expressed in a more temporal and spatially-specific manner, indicating their potential to serve as novel biomarkers $[16,17]$.

In the current study, we aimed to analyse the expression of coding and non-coding RNAs in TNBC and employ their intersection to develop a response score that would predict which TNBC patients will undergo pCR in response to NAC.

\section{Materials and Methods}

Gene expression profile of TNBC patients receiving NAC

We searched the publically available Gene Expression Omnibus (GEO) database to identify datasets where TNBC patients received NAC. Only datasets from the Affymetrix human genome U133 plus 2 microarray platform were interrogated, since it is widely used and includes 54000 probe sets that cover most region of human genome. Datasets were filtered according to the following criteria: 1) expression assay was performed with HG-U133 plus2 microarray, 2) TNBC patients received NAC, 3) data included about ER, PR, and HER status and response to NAC, 4) $\geq 5$ patients with pCR or not complete response (nCR) to NAC. Accordingly only the GSE32646 dataset [18] met these criteria. It consists of 115 breast cancer patients, of which 26 are TNBC (10 pCR, 16 nCR). Only the 26 TNBC patients were included for analysis.

Microarray data analysis and IncRNA profile

Differentially expressed lncRNAs and coding genes were calculated with the online GEO2R tool (http:// www.ncbi.nlm.nih.gov/geo/geo2r/). To analyse lncRNA expression we employed a pipeline to annotate HGU133 Plus 2.0 probe set as reported previously [19]. Briefly, the NetAffx Annotation Files (HG-U133 Plus 2.0 Annotations, CSV format) were downloaded and the probe IDs were mapped to annotation files, then probe 


\section{Cellular Physiology Cell Physiol Biochem 2018;48:2539-2548 \begin{tabular}{ll|l} 
and Biochemistry Published onlIne: 16 August, 2018 & $\begin{array}{l}\text { (c) } 2018 \text { The Author(s). Published by S. Karger AG, Basel } \\
\text { www.karger.com/cpb }\end{array}$
\end{tabular}}

ID-centric data was matched with annotations of database accession IDs, including RefSeq and Ensembl. Noncoding transcripts were further filtered out according to transcript types [19].

\section{Bioinformatic analyses}

Genomic location data of differentially expressed IncRNAs were submitted online to the GREAT website (http://bejerano.stanford.edu/great/public/html/). Enrichment of GREAT results were plotted by Cytoscape software [20]. Functional annotation (Gene Ontology (GO)) and pathway analyses of coding genes were performed using the Database for Annotation, Visualization, and Integrated Discovery (DAVID) website (https://david.ncifcrf.gov/home.jsp). Hierarchical cluster and heat map of differentially expressed lncRNAs were conducted using Cluster 3.0 with one minus correlation and average linkage methods.

\section{Statistical analyses}

Continuous variables were compared using Student's t test. Receiver operating characteristic (ROC) curves were constructed to assess sensitivity, specificity, and respective area under the curve (AUC) with 95\% confidential interval (CI). Statistical significance was taken as a two-tailed $P$ value $<0.05$ unless specifically indicated. The statistical analyses were performed using SPSS (version 18.0; SPSS Institute Inc., Chicago, IL, USA).

\section{Results}

\section{Patient characteristics}

Breast cancer patients in the GSE32646 dataset received NAC regimens consisting of paclitaxel, 5-fluorouracil, epirubicin and cyclophosphamide (paclitaxel followed by 5-fluorouracil, epirubicin and cyclophosphamide [P-FEC]). According to the ER, PR, and HER2 status criteria, 26 of the 115 patients in the dataset were identified as the TNBC subtype. Patients had a median age of 54.4, staging was from IIA to IIIB and 22 patients had lymph node involvement. Ten patients had pCR, and 16 had nCR.

\section{Differentially expressed IncRNAs between $p C R$ and $n C R$ patients}

We set $p<0.01$ as the threshold to filter for differentially expressed lncRNAs and coding genes. As shown, 172 coding genes and 84 lncRNAs were differentially expressed between pCR and nCR TNBC patients (Supplementary Table 1). For all supplemental material see www.karger.com/doi/10.1159/000492698. 85 coding genes were upregulated in pCR and 87 coding genes were downregulated; 39 lncRNAs were upregulated and 45 lncRNAs were downregulated in pCR compared with nCR (Fig. 1).

We then analyzed the potential functions of differentially expressed genes with functional annotation tools (GO and KEGG pathway analysis, Fig. 2). As shown, the biological processes of chromatin remodeling and regulation of axonogenesis were most significantly enriched. For the molecular function annotation results, genes with the function "drug binding" were enriched.

To predict the biological function of the differentially expressed lncRNAs, the genomic regions enrichment

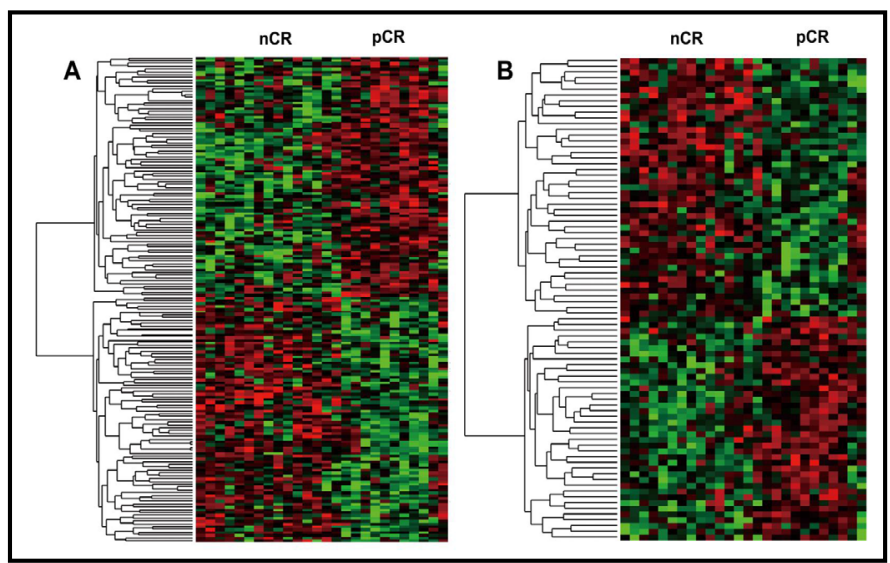

Fig. 1. Heatmap of differentially expressed coding genes (A) and IncRNAs (B) between pCR and nCR TNBC patients. Red: upregulated; green: downregulated. 


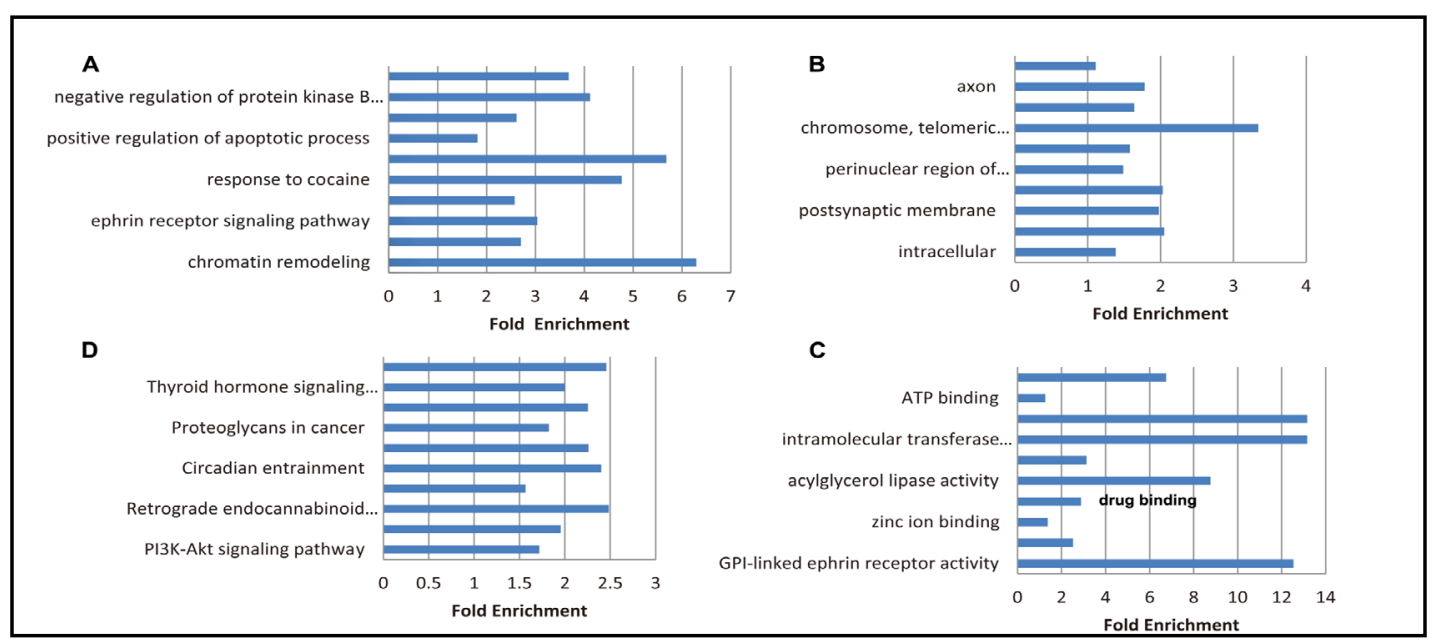

Fig. 2. Functional annotation of differentially expressed coding genes. A: biological process; B: cellular component; C: molecular function; D: KEGG pathway.

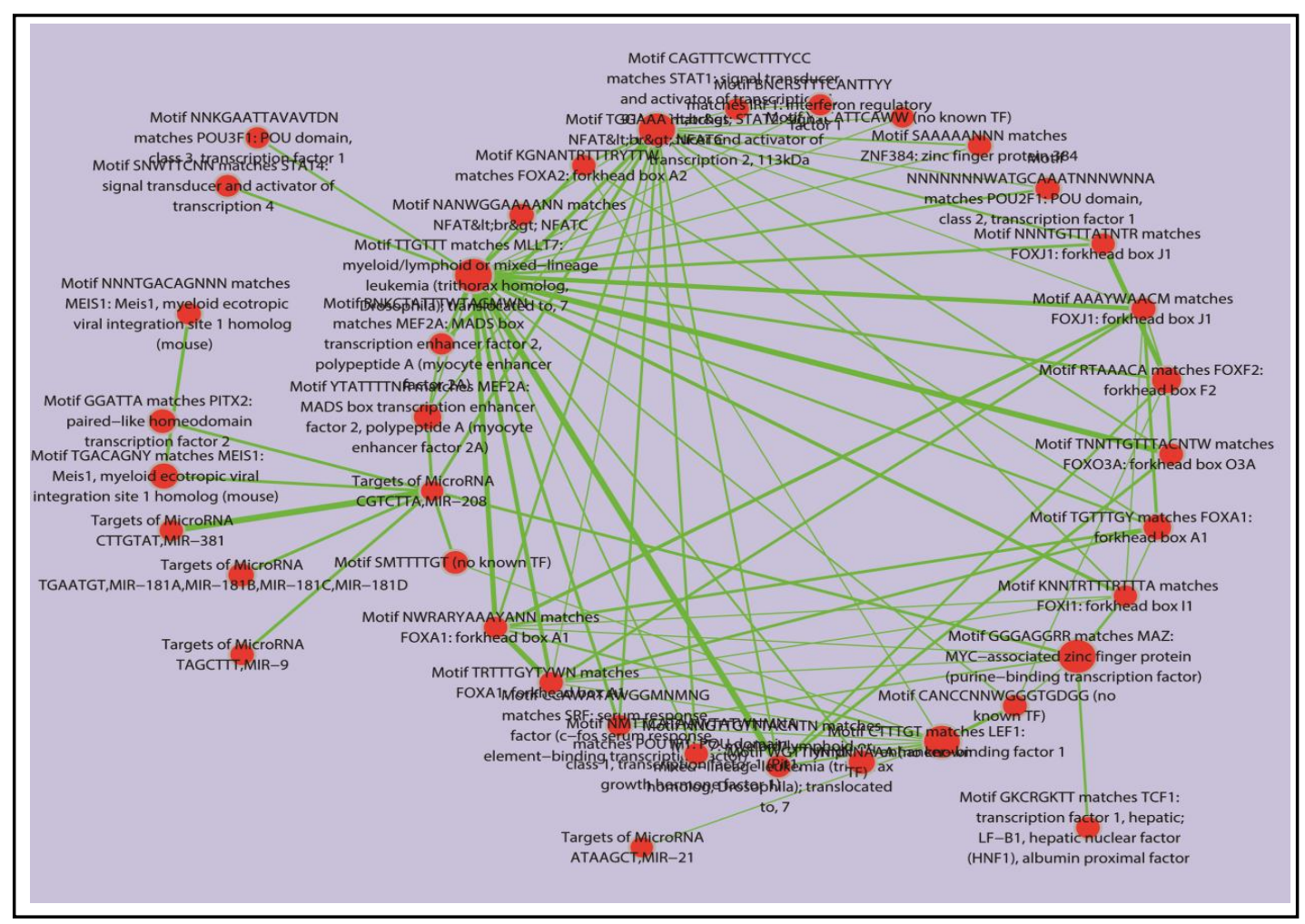

Fig. 3. GREAT analysis of differentially expressed lncRNAs. Many binding motifs of transcription factors are enriched nearby the genomic region of differentially expressed lncRNAs.

of annotations tool (GREAT)[21] was performed. Most differential lncRNAs were located near transcription start sites, which is consistent with previous reports that lncRNAs are actively transcribed from human genome. Additionally, the GREAT output suggests there are various binding sites of transcription factors within genomic region of lncRNAs (Fig. 3). The identified transcription factors included those known to have critical roles in breast cancer, for example FOXA1 [22], indicating these lncRNAs may also play important roles. 


\section{Cellular Physiology Cell Physiol Biochem 2018;48:2539-2548 \begin{tabular}{l|l|l} 
DOI: 10.1159/000492698 & $\begin{array}{l}\text { O 2018 The Author(s). Published by S. Karger AG, Basel } \\
\text { www.karger.com/cpb }\end{array}$
\end{tabular} \\ Wang et al.: A IncRNA-mRNA Signature Predicts NAC Response in TNBC}

Development of a response score to predict response to NAC

We first filtered potential lncRNAs and mRNAs that could predict response to NAC. Differentially expressed lncRNAs or coding genes with $p$ value $<0.01$ were first selected, and fold change $>2$ or $<-2$ was set to identify differentially expressed lncRNAs, and fold change $>4$ or $<-4$ was set to identify differentially expressed coding genes. For lncRNAs, we further selected those with HGNC gene symbol and transcript type of "antisense", "IncRNA", "processed pesudogene", "unprocessed pseudogene", and "transcribed unprocessed pseudogene". This process identified 23 IncRNAs and 15 coding genes for subsequent ROC analysis (Table 1 and Table 2). ROC was performed for each IncRNA and coding gene to assess their predictive value for NAC. As shown in Table 3 and Table 4, only lncRNA BPESC1, coding genes WDR72 and GADD45A showed excellent predictive efficacy.

With these 3 genes, we developed a "Response Score" for NAC in TNBC patients, response score $(\mathrm{RS})=2.595 *$ BPESC1-1.09*WDR72-1.428*GADD45A-0.731. As shown, the response score could significantly distinguish pCR and nCR patients with AUC of $0.931(p<0.01)$ (Fig. 4). Patients with high RS were more likely to have pCR. According to ROC analysis, an optimal cut-off of 0.541 was determined, and the predictive sensitivity and specificity of response score was 0.8 and 0.9 , respectively. We then evaluated our response score against the entire GSE32646 dataset including non-TNBC cases. As shown, response scores between pCR and nCR were statistically different among TNBC patients (Fig. 5), whereas response scores were not statistically different between PCR and nCR in patients with tumors positive for ER, PR, or HER2 overexpression.

\begin{tabular}{|c|c|c|c|c|c|c|}
\hline Table & HGNC symbol & Transcript stable ID & P.Value & $\log \mathrm{FC}$ & Transcript type & Transcript length \\
\hline & TSPEAR-AS2 & ENST00000330490 & 0.005334 & 2.542854 & antisense & 823 \\
\hline IncRNAs & FAR1P1 & ENST00000427163 & 0.001067 & 1.896832 & processed_pseudogene & 934 \\
\hline identified for & TPT1P8 & ENST00000510120 & 0.002824 & 1.718356 & unprocessed_pseudogene & 555 \\
\hline & ANP32C & ENST 00000512835 & 0.005074 & 1.08722 & processed_pseudogene & 705 \\
\hline analysis. & CLSTN2-AS1 & ENST00000513309 & 0.005882 & 0.971401 & antisense & 2693 \\
\hline & LINC01857 & ENST00000429730 & 0.001097 & 0.813998 & lincRNA & 492 \\
\hline I010 cinang & LINC01588 & ENST00000623502 & 0.004206 & 0.749833 & lincRNA & 975 \\
\hline lincRNA: large & BPESC1 & ENST00000418282 & 0.002015 & 0.724564 & lincRNA & 3522 \\
\hline & LINC00452 & ENST00000609661 & 0.007386 & 0.629585 & lincRNA & 2896 \\
\hline intergenic RNA & LINC02387 & ENST00000541749 & 0.008513 & 0.570136 & lincRNA & 868 \\
\hline & L3MBTL4-AS1 & ENST00000578427 & 0.00256 & -0.64378 & lincRNA & 2044 \\
\hline & SPATA41 & ENST00000558307 & 0.002081 & -0.80954 & lincRNA & 1252 \\
\hline & MST1P2 & ENST00000457982 & 0.002379 & -0.90345 & unprocessed_pseudogene & 2291 \\
\hline & RBMY2BP & ENST00000451071 & 0.009828 & -0.98378 & transcribed_unprocessed_pseudogene & 1156 \\
\hline & LINC01592 & ENST00000518540 & 0.008176 & -1.01895 & lincRNA & 2367 \\
\hline & NFIA-AS2 & ENST00000438559 & 0.008628 & -1.23862 & antisense & 1275 \\
\hline & CSMD2-AS1 & ENST00000425631 & 0.009892 & -1.29474 & antisense & 1367 \\
\hline & UBBP2 & ENST00000376781 & 0.007114 & -1.31044 & processed_pseudogene & 231 \\
\hline & LINC00593 & ENST00000558385 & 0.008152 & -1.31972 & lincRNA & 763 \\
\hline & GAS5 & ENST00000449289 & 0.008703 & -1.36826 & lincRNA & 542 \\
\hline & SOX1-0T & ENST00000421423 & 0.006632 & -1.62168 & lincRNA & 545 \\
\hline & FAM53B-AS1 & ENST00000448422 & 0.007983 & -1.71488 & antisense & 1491 \\
\hline & LINC01847 & ENST00000522627 & 0.000654 & -2.54338 & antisense & 5607 \\
\hline
\end{tabular}

Table 2. 15 coding genes identified for ROC analysis. FC: fold change

\begin{tabular}{lcccc}
\hline HGNC symbol & $\operatorname{logFC}$ & Transcript stable ID & Chromosome & Transcript length \\
\hline PCDHB1 & 2.926422 & ENST00000306549 & chr5 & 8210 \\
RGS11 & 2.650471 & ENST00000397770 & chr16 & 2390 \\
GADD45A & 2.394995 & ENST00000370986 & chr1 & 1496 \\
ZNF614 & 2.372718 & ENST00000356322 & chr19 & 1293 \\
NEURL4 & 2.224102 & ENST00000315614 & chr17 & 5182 \\
HNRNPA0 & 2.18639 & ENST00000314940 & chr5 & 8726 \\
C4orf3 & 2.021667 & ENST00000399075 & chr4 & 2960 \\
PCOTH & -2.02016 & ENST00000382133 & chr13 & 805 \\
CABP4 & -2.14612 & ENST00000438189 & chr11 & 1426 \\
S100A12 & -2.18748 & ENST00000368737 & chr1 & 518 \\
MED14 & -2.20079 & ENST00000324817 & chrX & 7984 \\
KIAA1210 & -2.32596 & ENST00000402510 & chrX & 7824 \\
CCL15 & -2.42104 & ENST00000631730 & Chr7 & 718 \\
COL20A1 & -2.43183 & ENST00000422202 & chr20 & 8097 \\
WDR72 & -2.4617 & ENST00000396328 & chr15 & 7507
\end{tabular}


Wang et al.: A IncRNA-mRNA Signature Predicts NAC Response in TNBC

Table 3. AUC of 23 lncRNAs. AUC: area under curve, *significant association

\begin{tabular}{lcccc}
\hline lncRNA & Area & Std. Errora & P value & $95 \%$ CI \\
\hline NFIA-AS2 & 0.494 & 0.118 & 0.958 & $0.263-0.724$ \\
SOX1-OT & 0.513 & 0.114 & 0.916 & $0.289-0.736$ \\
LINC01847 & 0.631 & 0.115 & 0.268 & $0.405-0.858$ \\
FAM53B-AS1 & 0.513 & 0.133 & 0.916 & $0.252-0.773$ \\
GAS5 & 0.631 & 0.113 & 0.268 & $0.41-0.853$ \\
FAR1P1 & 0.606 & 0.115 & 0.37 & $0.381-0.831$ \\
CSMD2-AS1 & 0.587 & 0.114 & 0.461 & $0.365-0.81$ \\
LINC01592 & 0.588 & 0.113 & 0.461 & $0.365-0.81$ \\
LINC00593 & 0.481 & 0.116 & 0.874 & $0.254-0.709$ \\
UBBP2 & 0.55 & 0.119 & 0.673 & $0.317-0.783$ \\
TSPEAR-AS2 & 0.594 & 0.117 & 0.429 & $0.364-0.823$ \\
ANP32C & 0.638 & 0.115 & 0.246 & $0.412-0.863$ \\
BPESC1 & 0.825 & 0.093 & $0.006 *$ & $0.635-1$ \\
LINC01588 & 0.562 & 0.116 & 0.598 & $0.336-0.789$ \\
LINC00452 & 0.531 & 0.118 & 0.792 & $0.3-0.763$ \\
RBMY2BP & 0.575 & 0.115 & 0.527 & $0.349-0.801$ \\
LINC02387 & 0.562 & 0.123 & 0.598 & $0.321-0.804$ \\
L3MBTL4AS1 & 0.631 & 0.116 & 0.268 & $0.404-0.858$ \\
SPATA41 & 0.619 & 0.123 & 0.317 & $0.378-0.859$ \\
LINC01857 & 0.475 & 0.115 & 0.833 & $0.25-0.7$ \\
MST1P2 & 0.556 & 0.115 & 0.635 & $0.331-0.781$ \\
CLSTN2AS1 & 0.575 & 0.114 & 0.527 & $0.352-0.798$ \\
TPT1P8 & 0.687 & 0.109 & 0.114 & $0.473-0.902$ \\
\hline
\end{tabular}

Table 4. AUC of 15 coding genes. AUC: area under curve, *significant association

\begin{tabular}{lcccc}
\hline Gene & AUC & Std. Errora & P value & $95 \%$ CI \\
\hline GADD45A & 0.794 & 0.094 & $0.013^{*}$ & $0.609-0.978$ \\
ZNF614 & 0.531 & 0.117 & 0.792 & $0.303-0.76$ \\
KIAA1210 & 0.481 & 0.117 & 0.874 & $0.252-0.711$ \\
HNRNPA0 & 0.481 & 0.118 & 0.874 & $0.249-0.713$ \\
CABP4 & 0.756 & 0.097 & 0.031 & $0.566-0.947$ \\
NEURL4 & 0.612 & 0.114 & 0.343 & $0.39-0.835$ \\
PCOTH & 0.631 & 0.11 & 0.268 & $0.416-0.847$ \\
MED14 & 0.563 & 0.127 & 0.598 & $0.313-0.812$ \\
RGS11 & 0.525 & 0.122 & 0.833 & $0.285-0.765$ \\
C4orf3 & 0.488 & 0.128 & 0.916 & $0.238-0.737$ \\
S100A12 & 0.494 & 0.12 & 0.958 & $0.259-0.729$ \\
PCDHB1 & 0.5 & 0.116 & 1 & $0.272-0.728$ \\
CCL15 & 0.506 & 0.117 & 0.958 & $0.278-0.735$ \\
WDR72 & 0.756 & 0.096 & $0.031 *$ & $0.569-0.944$ \\
COL20A1 & 0.594 & 0.115 & 0.429 & $0.368-0.819$ \\
\hline
\end{tabular}

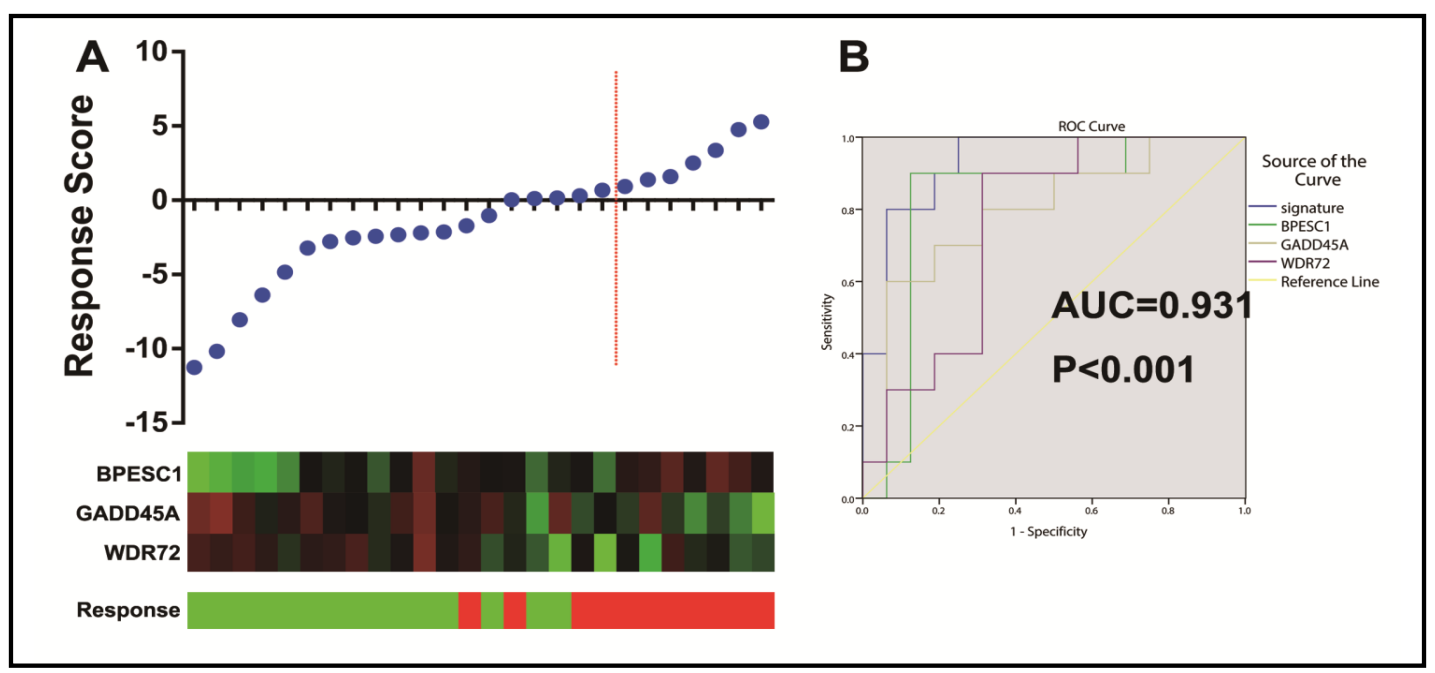

Fig. 4. Predictive efficacy of response score. Distribution of response score in 26 TNBC patients (A). For response, red represents pCR, green represents nCR. (B) ROC analyses of response score, WDR72, GADD45A, and BPESC1, respectively. 


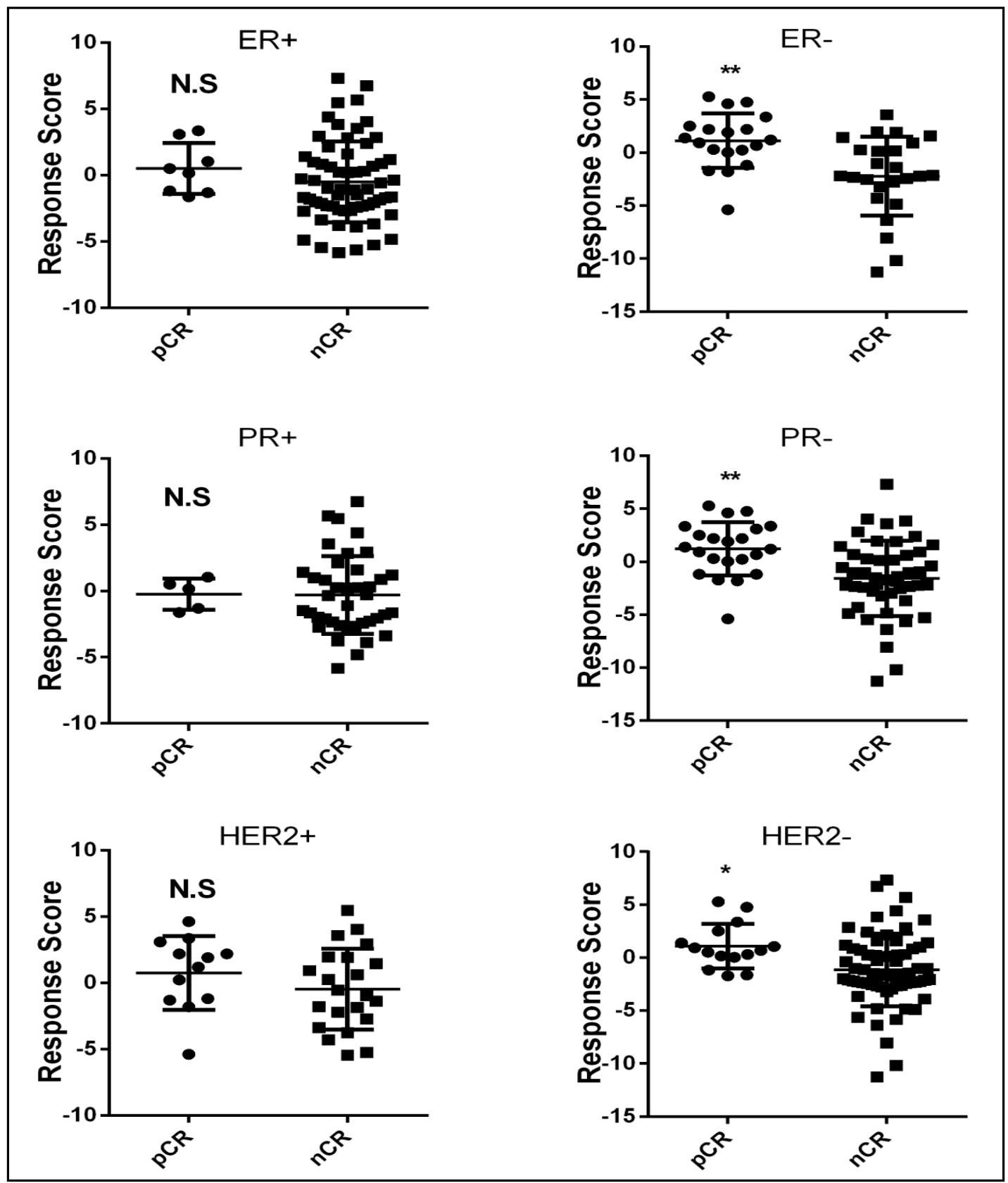

Fig. 5. Response score distribution among patients with different ER, PR, and HER2 status. N.S: not statistically significant; ${ }^{*} \mathrm{P}<0.05 ;{ }^{*} \mathrm{P}<0.01$.

\section{Discussion}

TBNC is an aggressive type of breast cancer with poor prognosis. It is reported about $30 \%$ of TNBC patients will eventually relapse and fail to response to conventional chemotherapies [3]. Numerous efforts have been made to develop tools for prediction of response to NAC in order to optimize chemotherapy for individuals. Some conventional clinical parameters may predict response to NAC, and a nomogram has been built [23]. Moreover, similar methods to our study have been applied before to predict pCR in NAC. Nevertheless, the predictive value of IncRNAs in TBNC patients treated with NAC has not been fully explored and our approach may provide some advantages. 


\section{Cellular Physiology Cell Physiol Biochem 2018;48:2539-2548 \begin{tabular}{ll|l} 
DOI: 10.1159/000492698 & O 2018 The Author(s). Published by S. Karger AG, Basel \\
www.karger.com/cpb
\end{tabular}

Here, we developed "Response Score", consisting of just one lncRNA and two coding genes for TNBC patients with NAC. The response score showed highly predictive efficacy in GSE32646 dataset (AUC=0.931). Wang et al. [24] previously developed a 36-lncRNA signature to predict NAC response in breast cancer, while the specific predictive efficacy was not determined in TNBC subgroup. Jiang et al. [25] also developed a signature consisting of 3 coding genes (FCGR1A, RSAD2, CHRDL1) and 2 lncRNAs (HIF1A-AS2, AK124454) to predict NAC response in TNBC patients. Compared with Jiang, our response score consists of one lncRNA and two coding genes which as a small gene signature may be more clinically feasible to measure with conventional instrumentation and approaches. However, the main shortcoming of our study is that our response score was not independently validated in other datasets and further validation is therefore needed.

Our response score consists of 2 coding genes, GADD45A and WDR72. GADD45A is a member of a group of genes whose transcript levels are increased following stressful growth arrest conditions and treatment with DNA-damaging agents. Many chemotherapeutic agents act through inducing DNA damage including those used here as NAC (5-fluorouracil, epirubicin and cyclophosphamide). GADD45A functions in DNA repair and it has also been confirmed it plays a role in promoting DNA methylation [26, 27]. On this basis, GADD45A is a logical candidate to show predictive efficacy to NAC (Table 4). In addition to GADD45A, GO analysis showed genes involved in chromatin remodeling were enriched among differentially expressed coding genes, suggesting epigenetic modification may play important roles in chemotherapy resistance. On the other hand, the exact function of WDR72 is still unknown. The WDR72 protein can act as a protein scaffold for protein-protein interactions and mutation of WDR72 is associated with amelogenesis imperfect. The role of WDR72 in cancers has been poorly investigated. It is reported that WDR72 is involved in a gene signature of 19 genes, which could be used for diagnosis of esophageal cancer [28]. This suggests WDR72 might be a sensitive biomarker.

To identify lncRNAs of predictive value, our filtering approach yielded 23 lncRNAs for ROC analysis (Table 1). Among the 23 lncRNAs shortlisted only a few have been investigated in detail such as GAS5 [29] while the functions of most others like lncRNA BPESC1 are presently unknown. We included lncRNA BPESC1 in the response score since it showed excellent predictive efficacy. According to RefSeq [30], BPESC1 is located on chromosome 3 , and is transcribed as 3518nt from 3 exons and contains an open reading frame of 351 bp. The functional role of BPESC1 has not been investigated in breast cancer and further exploration is needed.

\section{Conclusion}

We profiled coding gene and lncRNA expressions in TNBC patients receiving NAC and developed a response score consisting of IncRNA BPESC1 and coding genes WDR72 and GADD45A. The response score efficiently predicted TNBC patients with pCR to NAC.

\section{Acknowledgements}

We thank Prof. Rick Thorne (Translational Research Institute, Henan Provincial People's Hospital, Zheng Zhou) for critical reading of the manuscript. We acknowledge the assistance of Han-Yu Biomed Research Center (Beijing, China) for bioinformatic analyses.

This study was supported by grants from Science and Technology Research Project of Department of Education of Liaoning Province (grant number:LK201604) and Natural Science Foundation of Jiangsu Province (grant number: BK20151287). 


\section{Cellular Physiology Cell Physiol Biochem 2018;48:2539-2548 \begin{tabular}{ll|l} 
and BiOChemistry & $\begin{array}{l}\text { DOI: 10.1159/000492698 } \\
\text { Published online: 16 August, } 2018\end{array}$ & $\begin{array}{l}\text { (C) } 2018 \text { The Author(s). Published by S. Karger AG, Basel } \\
\text { www.karger.com/cpb }\end{array}$ \\
\hline
\end{tabular}}

Wang et al.: A IncRNA-mRNA Signature Predicts NAC Response in TNBC

\section{Disclosure Statement}

The authors declare no conflict of interests.

\section{References}

1 Harbeck N, Gnant M: Breast cancer. Lancet 2017;389:1134-1150.

-2 Kaufmann M, von Minckwitz G, Bear HD, Buzdar A, McGale P, Bonnefoi H, Colleoni M, Denkert C, Eiermann W, Jackesz R, Makris A, Miller W, Pierga JY, Semiglazov V, Schneeweiss A, Souchon R, Stearns V, Untch M, Loibl S: Recommendations from an international expert panel on the use of neoadjuvant (primary) systemic treatment of operable breast cancer: New perspectives 2006. Ann Oncol 2007;18:1927-1934.

-3 Dent R, Trudeau M, Pritchard KI, Hanna WM, Kahn HK, Sawka CA, Lickley LA, Rawlinson E, Sun P, Narod SA: Triple-negative breast cancer: Clinical features and patterns of recurrence. Clin Cancer Res 2007;13:44294434.

4 Venkitaraman R: Triple-negative/basal-like breast cancer: Clinical, pathologic and molecular features. Expert Rev Anticanc 2010;10:199-207.

5 Carey L, Winer E, Viale G, Cameron D, Gianni L: Triple-negative breast cancer: Disease entity or title of convenience? Nat Rev Clin Oncol 2010;7:683-692.

6 Fisher B, Brown A, Mamounas E, Wieand S, Robidoux A, Margolese RG, Cruz AB, Jr, Fisher ER, Wickerham DL, Wolmark N, DeCillis A, Hoehn JL, Lees AW, Dimitrov NV: Effect of preoperative chemotherapy on localregional disease in women with operable breast cancer: Findings from national surgical adjuvant breast and bowel project b-18. J Clin Oncol 1997;15:2483-2493.

7 Sachelarie I, Grossbard ML, Chadha M, Feldman S, Ghesani M, Blum RH: Primary systemic therapy of breast cancer. Oncologist 2006;11:574-589.

-8 Yin WJ, Lu JS, Di GH, Lin YP, Zhou LH, Liu GY, Wu J, Shen KW, Han QX, Shen ZZ, Shao ZM: Clinicopathological features of the triple-negative tumors in chinese breast cancer patients. Breast Cancer Res $\mathrm{Tr}$ 2009;115:325-333.

-9 Tsai MC, Spitale RC, Chang HY: Long intergenic noncoding rnas: New links in cancer progression. Cancer Res 2011;71:3-7.

10 Ponting CP, Oliver PL, Reik W: Evolution and functions of long noncoding rnas. Cell 2009;136:629-641.

11 Wilusz JE, Sunwoo H, Spector DL: Long noncoding rnas: Functional surprises from the rna world. Gene Dev 2009;23:1494-1504.

12 Qiu MT, Hu JW, Yin R, Xu L: Long noncoding rna: An emerging paradigm of cancer research. Tumor Biol 2013;34:613-620.

13 Esteller M: Non-coding rnas in human disease. Nat Rev Genet 2011;12:861-874.

14 Gupta RA, Shah N, Wang KC, Kim J, Horlings HM, Wong DJ, Tsai MC, Hung T, Argani P, Rinn JL, Wang Y, Brzoska P, Kong B, Li R, West RB, van de Vijver MJ, Sukumar S, Chang HY: Long non-coding rna hotair reprograms chromatin state to promote cancer metastasis. Nature 2010;464:1071-1076.

15 Tsai MC, Manor O, Wan Y, Mosammaparast N, Wang JK, Lan F, Shi Y, Segal E, Chang HY: Long noncoding rna as modular scaffold of histone modification complexes. Science 2010;329:689-693.

-16 Van Roosbroeck K, Pollet J, Calin GA: Mirnas and long noncoding rnas as biomarkers in human diseases. Expert Rev Mol Diagn 2013;13:183-204.

17 Yu H, Xu Q, Liu F, Ye X, Wang J, Meng X: Identification and validation of long noncoding rna biomarkers in human non-small-cell lung carcinomas. J Thorac Oncol 2015;10:645-654.

18 Miyake T, Nakayama T, Naoi Y, Yamamoto N, Otani Y, Kim SJ, Shimazu K, Shimomura A, Maruyama N, Tamaki Y, Noguchi S: Gstp1 expression predicts poor pathological complete response to neoadjuvant chemotherapy in er-negative breast cancer. Cancer Sci 2012;103:913-920.

19 Zhang X, Sun S, Pu JK, Tsang AC, Lee D, Man VO, Lui WM, Wong ST, Leung GK: Long non-coding rna expression profiles predict clinical phenotypes in glioma. Neurobiol Dis 2012;48:1-8.

20 Shannon P, Markiel A, Ozier O, Baliga NS, Wang JT, Ramage D, Amin N, Schwikowski B, Ideker T: Cytoscape: A software environment for integrated models of biomolecular interaction networks. Genome Res 2003;13:2498-2504. 


\section{Cellular Physiology Cell Physiol Biochem 2018;48:2539-2548 \begin{tabular}{ll|l} 
DOI: 10.1159/000492698 & $\begin{array}{l}\text { O 2018 The Author(s). Published by S. Karger AG, Basel } \\
\text { www.karger.com/cpb }\end{array}$ \\
\hline
\end{tabular} \\ Wang et al.: A IncRNA-mRNA Signature Predicts NAC Response in TNBC}

-21 McLean CY, Bristor D, Hiller M, Clarke SL, Schaar BT, Lowe CB, Wenger AM, Bejerano G: Great improves functional interpretation of cis-regulatory regions. Nat Biotechnol 2010;28:495-501.

22 Augello MA, Hickey TE, Knudsen KE: Foxa1: Master of steroid receptor function in cancer. EMBO J 2011;30:3885-3894.

-23 Rouzier R, Pusztai L, Delaloge S, Gonzalez-Angulo AM, Andre F, Hess KR, Buzdar AU, Garbay JR, Spielmann M, Mathieu MC, Symmans WF, Wagner P, Atallah D, Valero V, Berry DA, Hortobagyi GN: Nomograms to predict pathologic complete response and metastasis-free survival after preoperative chemotherapy for breast cancer. J Clin Oncol 2005;23:8331-8339.

24 Wang G, Chen X, Liang Y, Wang W, Shen K: A long noncoding rna signature that predicts pathological complete remission rate sensitively in neoadjuvant treatment of breast cancer. Transl Oncol 2017;10:988997.

25 Jiang YZ, Liu YR, Xu XE, Jin X, Hu X, Yu KD, Shao ZM: Transcriptome analysis of triple-negative breast cancer reveals an integrated mrna-Incrna signature with predictive and prognostic value. Cancer Res 2016;76:2105-2114.

26 Krushkal J, Zhao Y, Hose C, Monks A, Doroshow JH, Simon R: Concerted changes in transcriptional regulation of genes involved in DNA methylation, demethylation, and folate-mediated one-carbon metabolism pathways in the nci-60 cancer cell line panel in response to cancer drug treatment. Clin Epigenetics 2016;8:73.

-27 Schuermann D, Weber AR, Schar P: Active DNA demethylation by DNA repair: Facts and uncertainties. DNA Repair 2016;44:92-102.

28 Warneckeeberz U, Metzger R, Hölscher AH, Drebber U, Bollschweiler E: Diagnostic marker signature for esophageal cancer from transcriptome analysis. Tumor Biol 2016;37:6349-6358.

29 Sun W, Yang Y, Xu C, Xie Y, Guo J: Roles of long noncoding rnas in gastric cancer and their clinical applications. J Cancer Res Clin 2016;142:2231-2237.

30 De Baere E, Fukushima Y, Small K, Udar N, Van Camp G, Verhoeven K, Palotie A, De Paepe A, Messiaen L: Identification of bpesc1, a novel gene disrupted by a balanced chromosomal translocation, $\mathrm{t}(3 ; 4)$ (q23;p15.2), in a patient with bpes. Genomics 2000;68:296-304. 